\title{
Distribution of Triarrhena lutarioriparia and its reserve characteristics of nitrogen and phosphorus in Dongting Lake
}

\author{
Youze $\mathrm{Xu}^{1}$, Guangyi $\mathrm{Fu}^{1}$,Nan Tang ${ }^{1}$, Zhonghao $\mathrm{He}^{2}$, Lincheng Jian ${ }^{1}$, and Yuanyuan Zhao ${ }^{1 *}$ \\ 1. Hunan Research Academy of Environmental Science, Hunan Provincial Key Laboratory of Water Pollution Control Technology, 410000 \\ Changsha Hunan, China \\ 2. Beijing Normal University-Hong Kong Baptist University United International College, 519000 Zhuhai Guangdong, China
}

\begin{abstract}
Triarrhena lutarioriparia, a typical and most abundant macrophyte in Dongting lake wetland, was in the state of abandonment following the papermaking industry revocation in the lake basin. In order to provide scientific basis for precise management of $T$. lutarioriparia, the $T$. lutarioriparia distribution charateristics in Dongting Lake and its storage characteristics of nutrients were investigated in this study. Remote sensing interpretation results showed that the total area of . lutarioriparia in Dongting Lake wetland was 58,450 ha, $48.31 \%$ of which distributed in South Doting Lake wetlands. The nutrients contents were significantly different in T. lutarioriparia tissues, ranking in the descending order of spikes (TN $27.90 \mathrm{mg} / \mathrm{g}$, TP $3.46 \mathrm{mg} / \mathrm{g}$ ) >leaves (TN $16.38 \mathrm{mg} / \mathrm{g}$, TP $2.11 \mathrm{mg} / \mathrm{g}$ ) > stems (TN $5.38 \mathrm{mg} / \mathrm{g}$, TP $0.85 \mathrm{mg} / \mathrm{g}$ ). The total P quantities in each $T$. lutarioriparia tissue were ranked in the order: stems $(560.26 \mathrm{t})>$ leaves $(396.52 \mathrm{t})>$ spikes $(284.67 \mathrm{t})$, while the total $\mathrm{N}$ quantities were within the range of $2170.02 \sim 2801.3 \mathrm{t}$. It was estimated that about $7712.99 \mathrm{t}$ of TN and $1241.45 \mathrm{t}$ of TP were annually removed from Dongting Lake by reaping T. lutarioriparia. The nutrients stored in the dead tissues of T. lutarioriparia might possess non-negligible impact on the water quality of Doting Lake.
\end{abstract}

\section{Introduction}

Dongting Lake is known as the "Kidney of the Yangtze River", and its runoff is about $1 / 3$ of the total runoff of the Yangtze River [1]. Dongting Lake is a very important natural flood storage reservoir and internationally important wetlands, bearing major responsibilities for water ecology safety in the middle and lower reaches of the Yangtze River Basin [1]. Aquatic plants are indispensable parts both for both the structure and function of lake ecosystems [2]. Triarrhena lutarioriparia, a unique fibrous perennial herbaceous macrophyte in China, widely distributed in Dongting lake wetland [3-5]. The ecological functions of Triarrhena lutarioriparia such as purification of water bodies are extremely important to the ecosystem of Dongting Lake wetland. Meanwhile, compared with Phragmites australis, T. lutarioriparia has higher biomass per unit area and excellent cellulose quality $[3,6]$. Thus, T. lutarioriparia has been applied as the main raw material for pulp production in Dongting Lake area since the early 1960s [7-10]. In order to protect Dongting Lake from pulping and papermaking wastewater pollution, an implementation plan was issued by Hunan Provincial People's Government for guiding exit of papermaking enterprises in Dongting Lake Area (Government Office Letter No. 36, 2018), requesting paper-making enterprises around Dongting Lake to fully withdraw from pulp production capacity and to withdraw from paper-making production capacity in 2019. The overall withdrawal of papermaking makes it difficult to develop alternative resource utilization methods for $T$. lutarioriparia in the lake area within a short time. Therefore, a large amount of T. lutarioriparia will stay uncut in the lake wetland, causing problems in how to manage and protect them from exerting non-negligible impact on the water quality of Doting Lake [11-13].

Mastering the distribution status and nutrient characteristics of $T$. lutarioriparia is highly essential to formulate an effective management for it [14]. However, as the artificial planting development of T. lutarioriparia in recent years, the current distribution of $T$. lutarioriparia in Dongting Lake is still unclear. Moreover, the nutrient characteristics in T. lutarioriparia have been given less concern. The lack of research on T. lutarioriparia greatly increases the difficulty in the precise management of $T$. lutarioriparia. Therefore, remote sensing interpretation methods were used in this study to explore the distribution characteristics of $T$. lutarioriparia in Dongting Lake wetland. The dry-weight biomass and nutrient contents of each T. lutarioriparia tissue in different areas of Dongting Lake were investigated, and the total quantities of nutrients stored in T. lutarioriparia were further calculated. Results obtained in this study can provide scientific basis and strong supports for management of $T$. lutarioriparia after the withdrawal of the paper industry in Dongting Lake district.

\footnotetext{
* Corresponding author. E-mail: zyyhjgc0601@163.com
} 


\section{Method and Material}

\subsection{Sample Collection and Pretreatment}

After preliminary investigation and research in November 2018, a global positioning system was used to locate $T$. lutarioriparia in the whole lake area of Dongting Lake, and 6 sampling points were selected to collect $T$. lutarioriparia samples. The stems, leaves, and spikes of each plant of $T$. lutarioriparia are separately processed and marked on site. Then the collected T. lutarioriparia samples are washed with ultrapure water, dried and weighed. After green removing at $105{ }^{\circ} \mathrm{C}$ for $30 \mathrm{~min}$, the plant samples were dried to constant weights at $80^{\circ} \mathrm{C}$. The dried samples were then placed in a desiccator, cooled to room temperature and weighed, and water contents of the plant samples were measured.

\subsection{Remote sensing interpretation of $T$. lutarioriparia resources in Dongting Lake}

The geological conditions and plant species of the Dongting Lake area were investigated. Furthermore, the variations in remote sensing pictures of T. lutarioriparia due to seasonal changes were analyzed. Based on the cloud analysis of difference in water levels due to seasonal changes and the remote sensing pictures, the distribution of $T$. lutarioriparia in Dongting Lake wetland was interpreted by applying the Landsat 8 OLI-TIRS image data $[15,16]$. The remote sensing images of the Dongting Lake area in early spring of 2018 were selected for interpretation, and ENVI 5.3 and ArcMap 10.2 software were used to process the images. The maximum likelihood method is used to supervise and classify the images through the visual method. In order to improve the accuracy of the interpretation work, the unclear distribution areas of $T$. lutarioriparia in Dongting Lake wetlands were clarified by on-site survey and sampling.

\subsection{Data analysis}

The total nitrogen (TN) and phosphorus (TP) contents in the remaining litter (leaves, stems and spikes) were measured using Kjeldahl digestion followed by colorimetric analysis. Data shown in the figures herein are averages. Analysis of the variance was performed by oneway ANOVA and two-tailed paired $t$ test using the PASW statistics software package version 18 (SPSS, Inc., Chicago, IL). Differences were considered significant when the significance level was $<0.05$ (e.g. $\alpha=0.05$ ).

\section{Result and Discussion}

\subsection{The distribution characteristic of $T$. lutarioriparia in Dongting Lake}

Comprehensively considering the three factors including T. lutarioriparia distribution, natural conditions and geographic location, six sampling points (D1-D6 seen in Figure 1) were set up in the field investigation for the precise interpretation of the distribution of $T$. lutarioriparia in the Dongting Lake area. Figure 1 illustrated the interpretation results of $T$. lutarioriparia distribution in Doting Lake wetland. The specify areas of T. lutarioriparia in different districts were shown in Table 1. The total distribution area of T. lutarioriparia in early 2018 was nearly 58,467 ha (Table 1). As shown in Table 1, the specify areas of $\mathrm{T}$. lutarioriparia in different districts were ranked in the descending order: South Dongting Lake $(50.40 \%)>$ East Dongting Lake $(31.39 \%)>$ West Dongting Lake (18.21\%). In the basin of South Dongting Lake, T. lutarioriparia with the area of $29,457.78$ ha was mainly distributed in district of Yuanjiang city, accounting for $95.8 \%$ of the total T. lutarioriparia in South Dongting Lake. In the basin of East Dongting Lake, the distribution area of T. lutarioriparia in Yueyang City and Xiangyin city has an area of 9,707.68 ha and 7,948.50 ha, accounting for $96.40 \%$ of the total distribution area in this basin. In the basin of West Dongting Lake, Triarrhena lutarioriparia was mainly distributed in Hanshou County followed by Anxiang County. Among all the districts in Dongting Lake basin, Yuanjiang City has the widest distribution area with $28,235.89$ ha of $T$. lutarioriparia, followed by Yueyang County (9,707.68 ha) and Xiangyin County $(7,948.5$ ha)

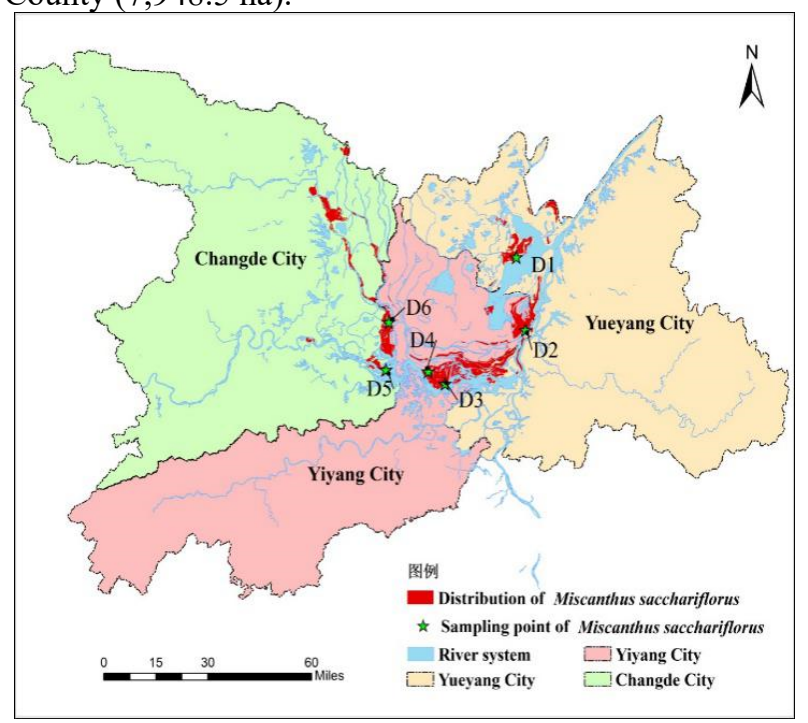

Fig1. Distribution status of T. lutarioriparia in Doting Lake wetland

Table1. Distribution area of T. lutarioriparia in different Doting Lake regions

\begin{tabular}{|c|c|c|c|}
\hline Lake & $\begin{array}{l}\text { District } \\
\text { name }\end{array}$ & $\begin{array}{c}\text { Distribution } \\
\text { area (ha) }\end{array}$ & Total area (ha) \\
\hline \multirow{3}{*}{$\begin{array}{l}\text { South Dongting } \\
\text { Lake }\end{array}$} & Ziyang & 28.07 & \multirow{3}{*}{29457.78} \\
\hline & Nanxian & 1193.82 & \\
\hline & Ruanjiang & 28235.89 & \\
\hline \multirow{4}{*}{ West Dongting Lake } & Anxiang & 2951.36 & \multirow{4}{*}{10646.45} \\
\hline & Jinshi & 32.15 & \\
\hline & Hanshou & 7252.43 & \\
\hline & Dingcheng & 410.51 & \\
\hline \multirow{3}{*}{ East Dongting Lake } & Junshan & 132.78 & \multirow{3}{*}{18345.86} \\
\hline & & & \\
\hline & Yueyang & 9707.68 & \\
\hline
\end{tabular}




\begin{tabular}{lll}
\hline & & \\
Xiangyin & 7948.50 \\
& Huarong & 557.00 \\
\hline
\end{tabular}

\subsection{Nitrogen and Phosphorus distribution in $T$. lutarioriparia}

Ten copies of each T. lutarioriparia tissue were collected from sampling sites (D1-D6). Basic properties including biomass and water content were statistically calculated and showed in Table 2. The proportion for dry-weight biomass of over-ground $T$. lutarioriparia tissues was ranked in the descending order of stems $(70.73 \%)>$ leaves $(20.98 \%)>$ spikes $(8.28 \%)$. The TN and TP contents of $T$. lutarioriparia in D1-D6 sampling sites of Doting Lake wetlands were demonstrated in Figure 2 and Figure 3, respectively. The TN $(5.76 \sim 11.07 \mathrm{mg} / \mathrm{g})$ and TP contents $(1.14 \sim 2.11 \mathrm{mg} / \mathrm{g})$ varied siginificantly with different $T$. lutarioriparia tissues $(\mathrm{P}<0.05)$, both exhibiting the sequence of spikes $>$ leaves $>$ stems. The average contents of TP in spikes, leaves, stems and roots of T. lutarioriparia tissues were $3.76 \mathrm{mg} / \mathrm{g}, 2.07 \mathrm{mg} / \mathrm{g}, 0.85 \mathrm{mg} / \mathrm{g}$ and 2.08 $\mathrm{mg} / \mathrm{g}$, respectively. Meanwhile, the average contents of $\mathrm{TN}$ in spikes, leaves, stems and roots of $T$. lutarioriparia tissues were $27.58 \mathrm{mg} / \mathrm{g}, 15.37 \mathrm{mg} / \mathrm{g}, 4.42 \mathrm{mg} / \mathrm{g}$ and 6.23 $\mathrm{mg} / \mathrm{g}$, respectively. No significant differences were observed in the nutrient content of T. lutarioriparia from different area of Dongting Lake wetlands $(\mathrm{P}>0.05)$. The nutrient contents in rhizosphere soil where $T$. lutarioriparia grew were shown in Table 3. The TN and TP contents in rhizosphere soils were within the range of $11.8 \sim 13.4 \mathrm{mg} / \mathrm{g}$ and $6.13-11.1 \mathrm{mg} / \mathrm{g}$. There is a positive correlation (R2>0.99) between the nutrient contents in $T$. lutarioriparia and its rhizosphere soil.

Table2. Basic properties of T. lutarioriparia in Doting Lake wetlands

\begin{tabular}{ccc}
\hline Tissues & $\begin{array}{c}\text { Moisture } \\
\text { content } / \%\end{array}$ & $\begin{array}{c}\text { Dry-weight } \\
\text { biomass per } \\
\text { plant } / \mathrm{g}\end{array}$ \\
\hline Spikes & 12.96 & 10.10 \\
Leaves & 12.79 & 25.58 \\
Stems & 28.69 & 86.23 \\
Roots & 37.06 & 72.88 \\
\hline
\end{tabular}

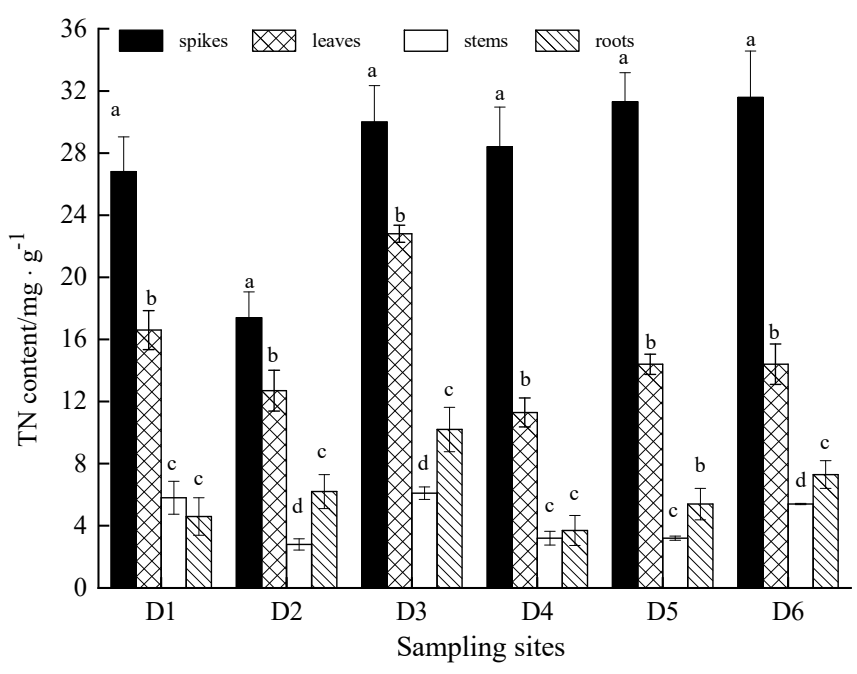

Fig2. TN content of T. lutarioriparia tissues in Dongting Lake

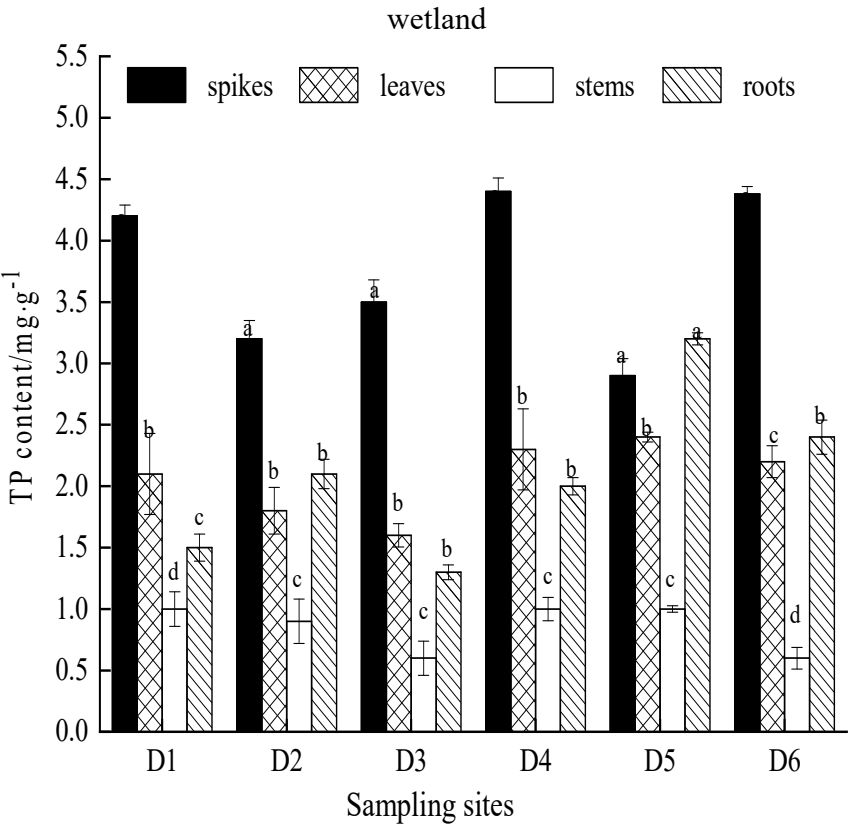

Fig3. TP content of T. lutarioriparia tissues in Dongting Lake wetland

Table3. Nitrogen and phosphorus content of rhizosphere soil in $\mathrm{T}$. lutarioriparia growing area

\begin{tabular}{ccc}
\hline $\begin{array}{c}\text { Sampling } \\
\text { sites }\end{array}$ & $\mathrm{TN} / \mathrm{mg} \cdot \mathrm{g}^{-1}$ & $\mathrm{TP} / \mathrm{mg} \cdot \mathrm{g}^{-1}$ \\
\hline $\mathrm{D} 1$ & 12.18 & 6.7 \\
D3 & 13.4 & 6.46 \\
D5 & 11.8 & 7.7 \\
\hline
\end{tabular}

\subsection{Quantities of Nitrogen and Phosphorus stored in $T$. lutarioriparia}

According to statistics, the total output of T. lutarioriparia in Dongting Lake is about 900,000 tons/year (dry weight). Based on the biomass proportion and the nutrient ( $\mathrm{N}$ and P) content of each T. lutarioriparia tissue, the annual yield and nutrient reserves of each T. lutarioriparia tissue were calculated and shown in Table 4 . The annual yields of the 
over-ground parts of T. lutarioriparia tissues in Dongting Lake wetland were 74,500 tons, 188,800 tons, and 636,700 tons for spikes, leaves and stems, respectively. The quantities of nitrogen and phosphorus that can be annually removed from Doting Lake by cutting the $T$. lutarioriparia were 7712.99 tons and 1241.45 tons, respectively. There was no significant difference in the total amount of nitrogen (2,170-2,801 tons/year) stored in different tissues of T. lutarioriparia in Dongting Lake. On the contrary, the phosphorus reserves of different $T$. lutarioriparia tissues were quite different, exhibiting the descending order of stems (560.26 tons/year) $>$ leaves (396.52 tons/year) $>$ spikes (284.67 tons/year). In the absence of harvesting, the dead tissues of the uncut $T$. lutarioriparia with large scale will lie down and decay in the lake water, and the release of T. lutarioriparia nutrients during decomposing process possesses non-negligible impact on the water quality of Doting Lake.

Table4. Annual output and nutrient reserves of $\mathrm{T}$. lutarioriparia tissues

\begin{tabular}{cccc}
\hline Tissues & Biomass $/\left({ }^{*} 10^{4} \mathrm{t}\right)$ & $\mathrm{N}$ Storage/t & P Storage/t \\
\hline Spikes & 7.45 & 2170.02 & 284.67 \\
& & & \\
Leaves & 18.88 & 2741.67 & 396.52 \\
Stems & 63.67 & 2801.3 & 560.26 \\
Total & 90 & 7712.99 & 1241.45 \\
\hline
\end{tabular}

\section{Conclusion}

The total growing area of $T$. lutarioriparia in Dongting Lake wetland was about 58,450 ha, and T. lutarioriparia mainly distributed in South Doting Lake wetlands, accounting for $50.40 \%$ of the total growing area. The annual yields (calculated in dry weight) of the over-ground parts of T. lutarioriparia tissues in Dongting Lake wetland were 74,500 tons, 188,800 tons, and 636,700 tons for spikes, leaves and stems, respectively. The nutrients showed similar distributing characteristics in over-ground tissues of T. lutarioriparia. Both the average contents of TN and TP exhibited the high-to-low sequence of spikes (TN $27.58 \mathrm{mg} / \mathrm{g}$, TP $3.76 \mathrm{mg} / \mathrm{g}$ ) > leaves (TN $15.37 \mathrm{mg} / \mathrm{g}$, TP $2.07 \mathrm{mg} / \mathrm{g}$ ) > stems (TN $4.42 \mathrm{mg} / \mathrm{g}$, TP $0.85 \mathrm{mg} / \mathrm{g}$ ). The quantities of nitrogen and phosphorus that can be annually removed from Doting Lake by cutting the T. lutarioriparia were 7712.99 tons and 1241.45 tons, respectively. Thus, the dead tissues of the uncut $T$. lutarioriparia with large amount of nutrient reserves may possess non-negligible impact on the water quality of Doting Lake.

\section{References}

1. S.M. Wang, H. S. Dou, China Lake Records. Science ress, Beijing, China (in Chinese)

2. P.E. O'Sullivan, C.S. Reynolds. Chapter 11. Aquatic Plants and Lake Ecosystems [M]//The Lakes Handbook, Limnology and Limnetic Ecology, 1, Blackwell Science Ltd ( 2007)
3. S.L. Chen, S.A. Renvoize, A new species and a new combination from China of Miscanthus (Poaceae), Kew Bulletin, 60(4),605-607 (2011)

4. G. Han, G. Zhang, On the feedaimed potentialities and further development exploitation of Phragmites communis and Miscanthus sacchariflorus in the region of DongTing lake, Resources and Environment in the Yangtze Basin, 232-236 (1998)

5. Liou L, Cao X, Studies on the Autotetraploid of Triarrhena lutarioriparia, Acta Genetica Sinica, 24, 544-549 (1997)

6. N. Dang Z. Huang, H. Li, Advances in Biology and Applications of Fiber Plant Triarrhena lutarioriparia,[J], Tropical and Subtropical Botany, 20(4), 418-424 (2012, in Chinese)

7. X. Chen, L. Zhu, Z. Deng, et al., Effects of Clipping on Bud Bank and Population Regeneration of Triarrhena lutarioriparia in Dongting Lake Wetland, China[J], Wetlands, 1-8 (2020)

8. L. Liu, Unique parper-making raw materials in China: Triarrhena lutarioriparia, Plants, 17, 6-7 (1990)

9. Xianjun W. Study on the Comprehensive Utilization of Reeds in the South Dongting Lake Area, Agricultural Technology and Equipment, 2019. (in Chinese)

10. L. Liu, Chinese endemic papermaking materialsMiscathus lutarioriparius[J], Plant magazine, 5, 6-7 (1990, in Chinese)

11. Y. He, N. Song, H. L. Jiang, Effects of dissolved organic matter leaching from macrophyte litter on black water events in shallow lakes, Environmental Science and Pollution Research (2018)

12. E.M. Eid, K. H. Shaltout, Y.M. Al-Sodany, Decomposition dynamics of Phragmites australis litter in Lake Burullus, Egypt, Plant Species Biology, 29(1), 47-56 (2014)

13. H. P. van Dokkum, D. M. E. Slijkerman, L. Rossi, M. L. Costantini, Variation in the decomposition of Phragmites australis litter in a monomictic lake: the role of gammarids, Hydrobiologia, 482, 69-77. (2002)

14. Y. Xie, Y. Xie, H. Xiao, et al., Controls on Litter Decomposition of Emergent Macrophyte in Dongting Lake Wetlands[J], Ecosystems (2017)

15. R. C. Estoque, Y. Murayama, Classification and change detection of built-up lands from Landsat-7 ETM+ and Landsat-8 OLI/TIRS imageries: A comparative assessment of various spectral indices [J], Ecological Indicators, 56, 205-217 (2015)

16. H. Huang, L. Zhang, Z. Gao, The vegetation resource at the intertidal zone in Shanghai using remote sensing[J], Acta Ecologica Sinica, 25(10), 2686-2693. (2005, in Chinese) 